Session 2532

\title{
Evaluation of the Accuracy and Effectiveness of Portfolio Based Student Self-Assessment
}

\author{
Christopher S. Greene and Jeffrey A. Jalkio \\ Department of Engineering \\ University of St. Thomas
}

\begin{abstract}
$\underline{\text { Abstract }}$
One advantage of having clearly articulated learning objectives for courses is that students can focus on these objectives to help them unify course material. Unfortunately, students often ignore the stated course objectives and focus their attention on the specific work required to earn good grades from the instructor. Although there should be alignment between these specific grading opportunities and the course objectives, the connections are frequently lost on the students. The authors have previously presented a technique for shifting the student focus from the external validation of course grades to a self-assessment of accomplishment of course learning objectives. The current paper documents the effectiveness of the method based on data collected in twelve classes over three academic years by two professors and discusses enhancements that have been implemented.

The approach aims to tie the course grade directly to the student's self-assessment. At the beginning of the semester, students are given a detailed list of course learning objectives and a grading rubric that relates letter grades to demonstrated levels of accomplishment of these objectives rather than to percentage of points earned. During the course of the semester assignments are collected and graded as usual to provide formative feedback to the students. Twice each semester students are required to give the instructor a portfolio of work demonstrating accomplishment of the learning objectives and a summary evaluation specifying the letter grade earned and, most importantly, how the attached portfolio supports their selfassessment.
\end{abstract}

This paper will examine the correlation of student self-assessment with traditional grading and evaluate its effectiveness in altering student focus from obtaining good grades to achieving course objectives. The use of these self-assessment reports and portfolios for course and program assessment as part of an ABET review will also be discussed. 


\section{$\underline{\text { Introduction }}$}

The grading system evaluated in this paper was first presented at the 2002 ASEE annual conference $^{1}$. It is a portfolio based grading technique addressing three issues. First, how do we assign grades that provide accurate feedback to our students on their overall academic progress in achieving course objectives. Second, how do we assess the efficacy of our instruction so that we can improve our classes and document accomplishment of objectives for accreditation purposes. Third, how do we motivate student reflection on the material beyond memorization of formulae to the integration of math, science, and engineering topics into their mental toolbox.

Our previous paper reviewed studies of norm-referenced and criterion-referenced grading ${ }^{2,3,4}$ and presented a grading system in which students submit a self-assessment report at the middle and end of the semester reporting their level of mastery in each of the course learning objectives. This report includes references to specific accomplishments demonstrated in graded assignments (examinations, homework, and laboratory reports) that document their self-assessment.

The portfolio of supporting documentation also provides a tool for the assessment of the course. Portfolios in general have been long discussed in the literature of assessment and compared to other assessment tools ${ }^{5}$. Since these portfolios are collected and maintained by the student during the semester and each is accompanied by an assessment written by the student, these portfolios overcome several of the disadvantages described by previous authors ${ }^{6}$. In particular, these concerns include the time required for faculty evaluation of the portfolio, storage resources required if the portfolio is maintained by the institution and lack of compliance if the portfolio is maintained by the student.

This system of student self-assessment also addressed the third issue of seeking student ownership of the learning process. Work in this area has shown that self-assessment promotes reflection on the learning process ${ }^{7}$ but is not accurate. Since our system requires the student to provide evidence for their assessments, it should reduce the biases found in self-assessment. In particular, this system combines the advantages of formative evaluation of student work by the instructor and summative evaluation though self-assessment. It was also hoped that this approach would permit evaluation of attitudinal objectives ${ }^{8}$ that are difficult for the instructor to evaluate by other means.

\section{Accuracy of Self-Assessments}

The authors have employed this grading methodology in fourteen courses over the course of three academic years and have tracked correlation between student self-assessment and instructor assigned grades over this period. Because of the small class sizes at our institution, these results should not yet be considered to be statistically significant, but rather as preliminary indicators. For each class, the instructor calculates the student grades prior to reading the student self-assessment report. These grades are based on the usual averaging of points earned in the semester's assignments using a four point scale (i.e. $\mathrm{A}=4.0, \mathrm{~B}=3.0$, etc.). These instructor 
assigned grades are then compared to the student self-assessed grades which are based on demonstrated accomplishment of course objectives rather than points earned. We measure the accuracy of a student's self-assessed grade as the difference between the instructor's grade and the student's. It should be noted that this terminology assumes that the instructor's assessment is correct, but it is the best available reference for measurement ${ }^{9}$. We have tracked the overall accuracy of self-assessment as well as tracking accuracy vs. grade, variation of accuracy of a particular group of students over time, and variation of accuracy in a particular course over time.

Figure 1 shows the overall accuracy of student self-assessment in our courses based on 153 total grading opportunities ( 69 from midterm assessments, and the balance from final grades). Fifty two percent of student grades match instructor assigned grades, while $82 \%$ are within a single grade (e.g. B+ to A-) and $93 \%$ are within two grades. Interestingly, these percentages were virtually identical for the two instructors. The histogram also shows a small outlier group of 3 students whose self-assessed grades were significantly higher than that assigned by the instructor. These outliers were from midterm grades during the first year of our tests and the students clearly have 'learned' the standards required. In fact, early anecdotal evidence suggests that when first presented with this grading philosophy, students occasionally view it as an opportunity to request any grade they wish.

Figure 1 - Overall Accuracy of Student Self-Assessment

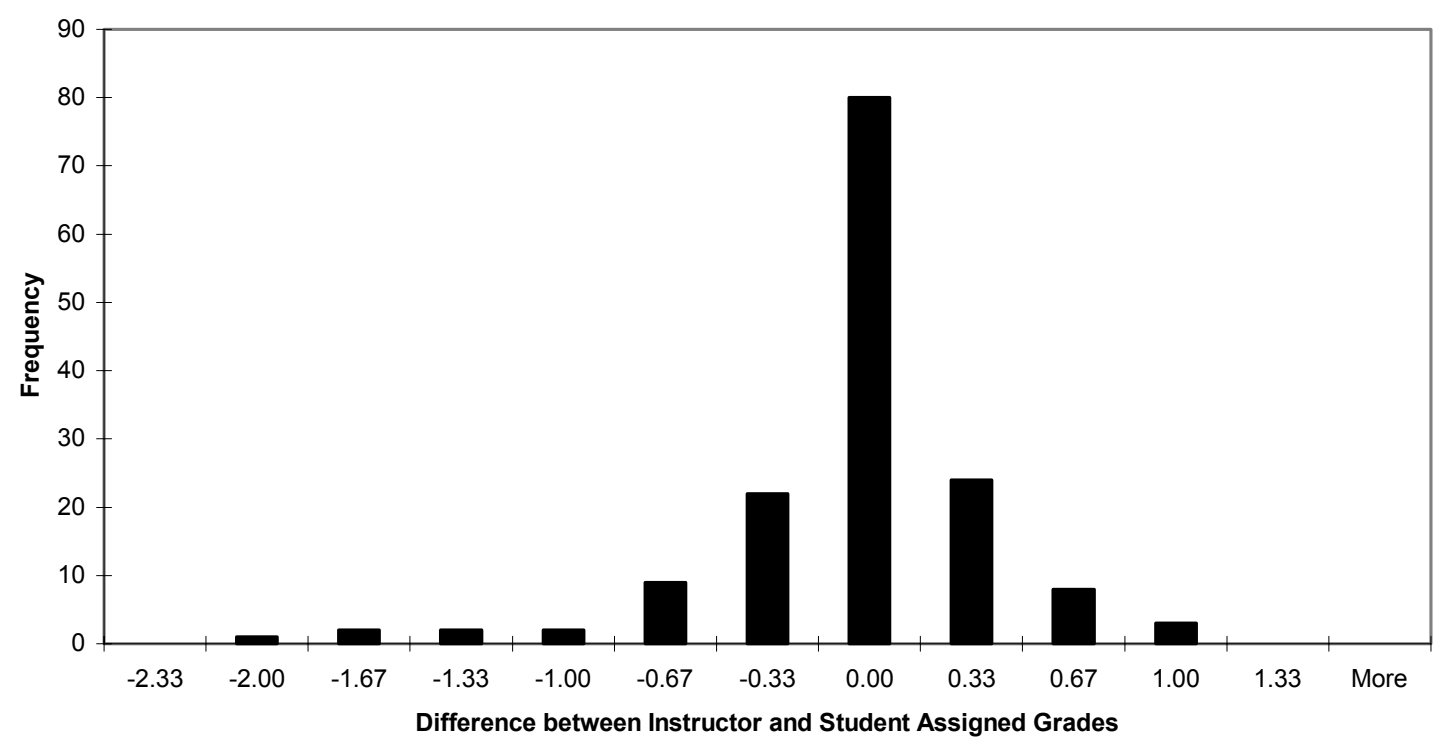

Figure 2 shows the correlation between accuracy of self-assigned grades with the grade earned in the course. It should be noted that as in other studies ${ }^{7}$, this graph appears to show that high performing students tend to underestimate their performance while lower performing students

Proceedings of the 2004 American Society for Engineering Education Annual Conference and Exposition Copyright (C) 2004, American Society for Engineering Education 
tend to overestimate. However, the correlation coefficient is only 0.29 so this conclusion is not supported statistically although it matches the subjective impressions of the authors.

Figure 2 - Correlation between Accuracy and Grade

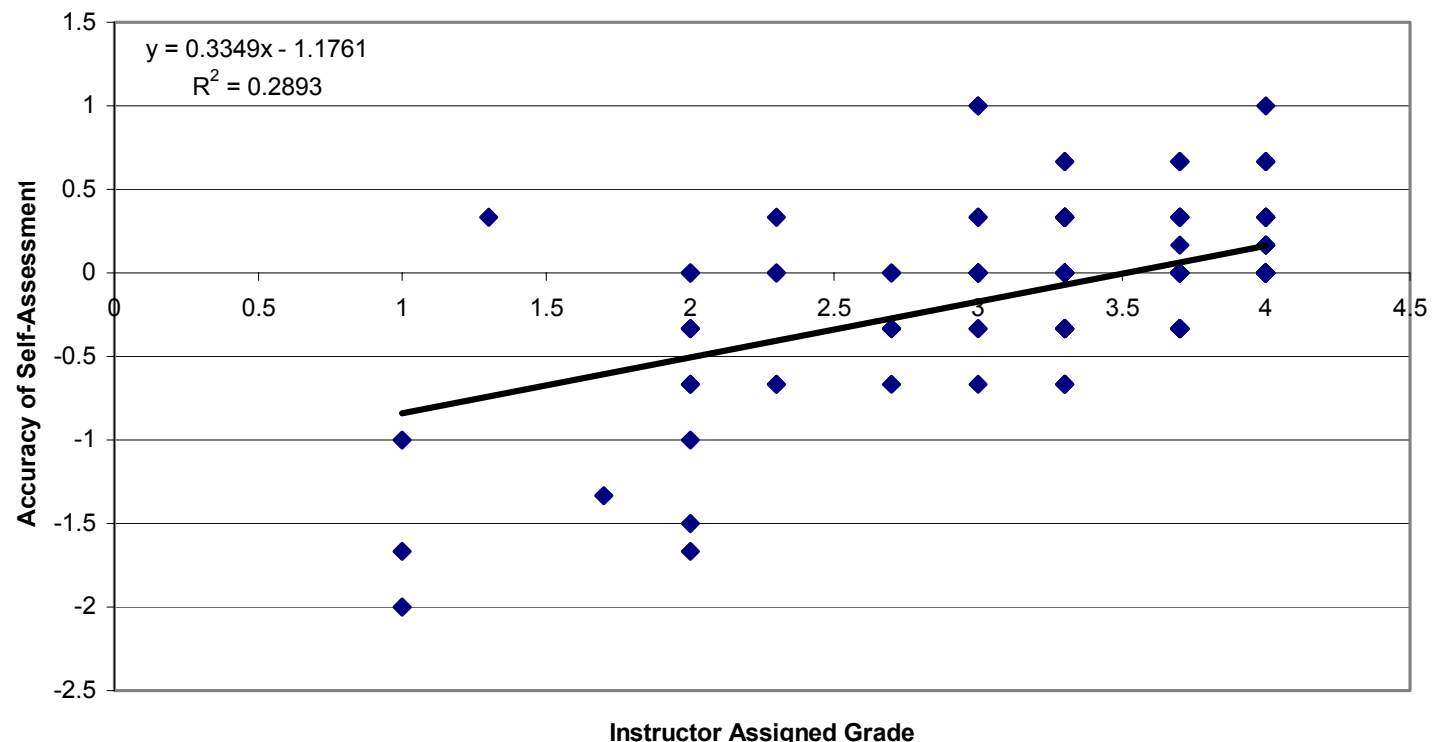

Figure 3 - Accuracy over time

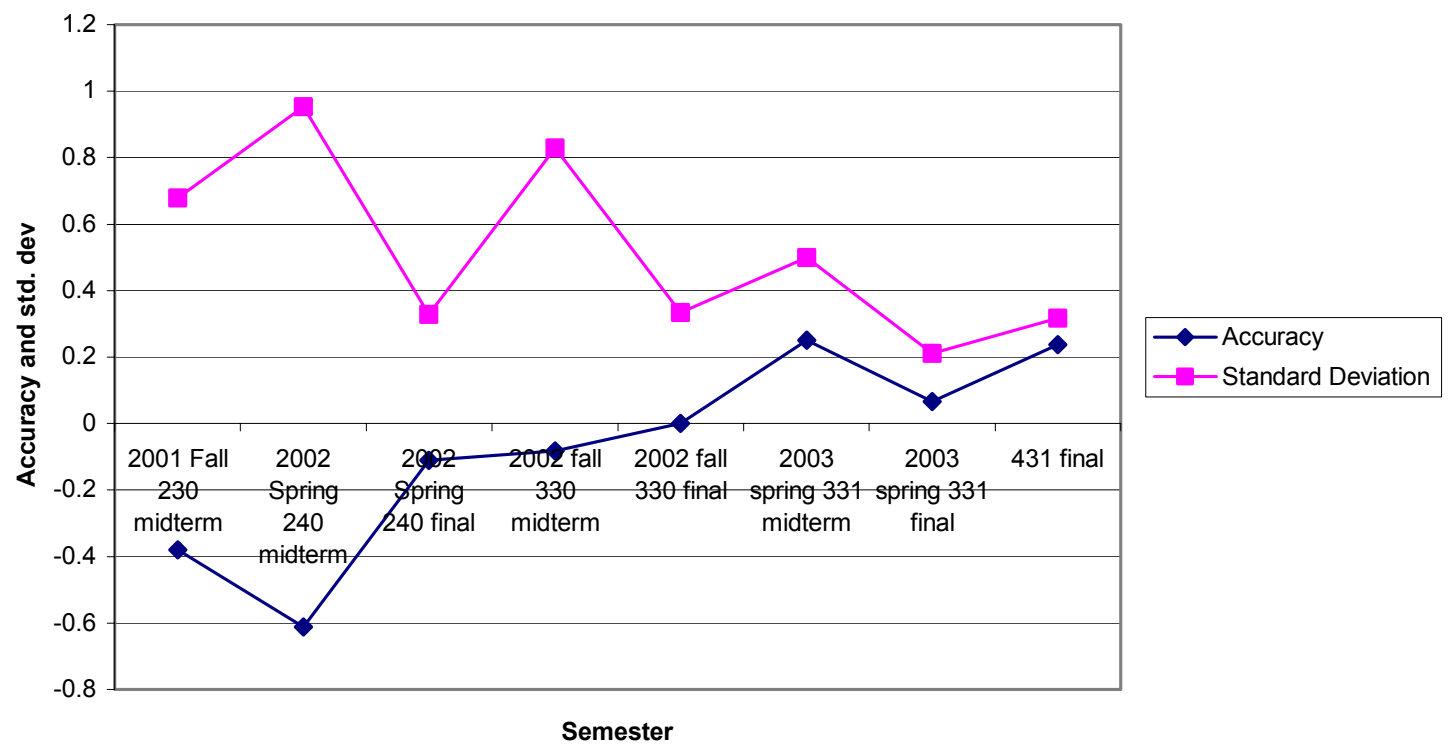

Proceedings of the 2004 American Society for Engineering Education Annual Conference and Exposition Copyright (C) 2004, American Society for Engineering Education 
Figure 3 shows how the accuracy of student self assessment varied over time for a single group of students (the graduating class of 2004). This appears to show a trend from overestimating grades to underestimating them as students learned the instructors' grading philosophy as well as learning from midterm to final grades.

Figure 4 shows the accuracy of student self-assessments in a single course (a sophomore level digital design class) over the three years of the study.

Figure 4 - Accuracy over Time for a Single Course

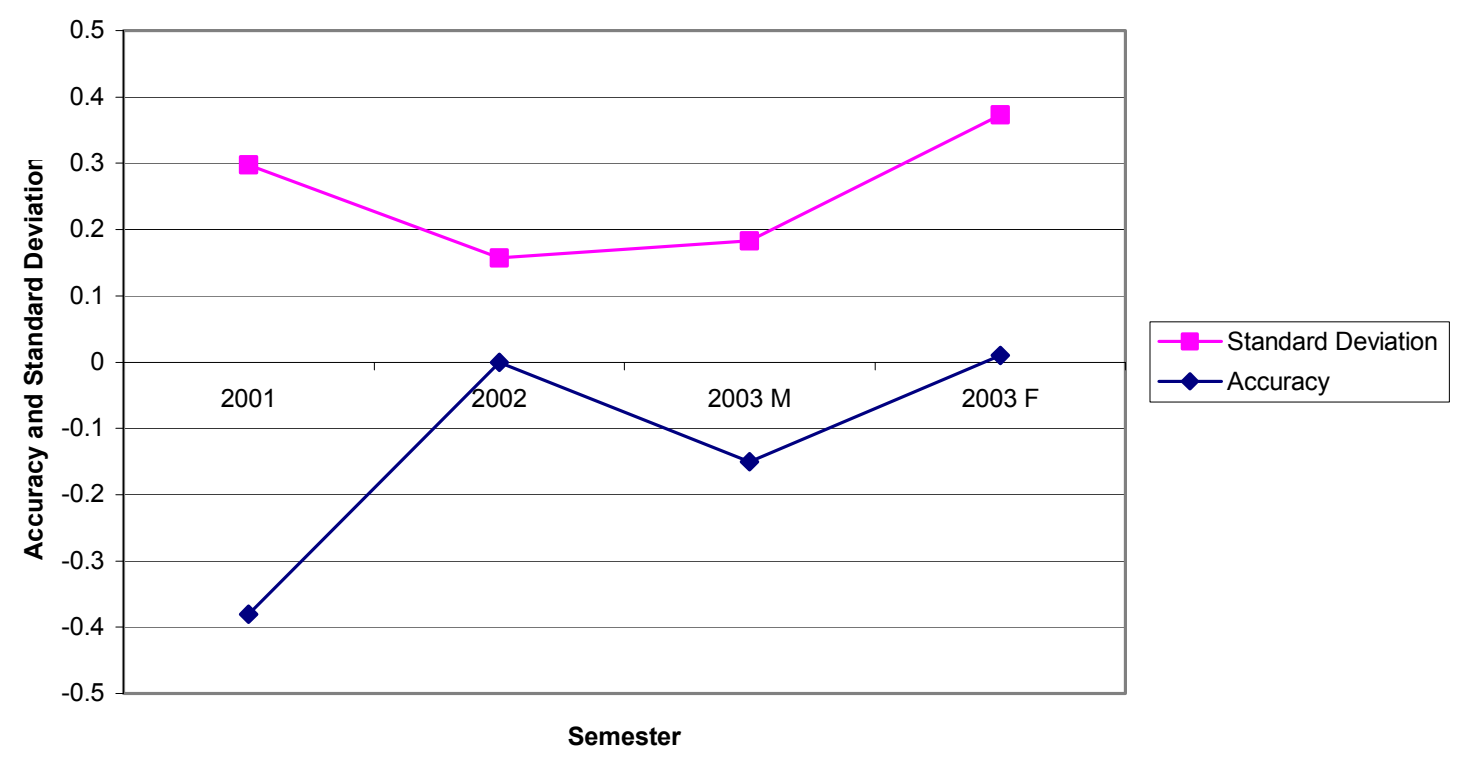

\section{Effectiveness of Self-Assessment}

Because of the small sample size thus far, the authors can provide only anecdotal evidence of the effectiveness of this grading technique. First, it is clear that this technique is not a "silver bullet" that resolves all difficulties in grading. The authors continue to experiment with modifications of the technique including the fusion of self-assessment with traditional grading, so that the accuracy of the student's self-assessment counts as some percentage of the points earned in the course. However, over the three year experiment, the author's have been able to make several observations on the effectiveness of the technique.

First, it has been observed that several things are needed for the technique to work. The preparation of self-assessments at mid-term as well as the end of the semester is an essential part of the technique. When the mid-term portfolio is not required, students tend to ignore self- 
assessment until the end of the semester. Similarly, as mentioned in our earlier paper, the technique requires very clear and measurable course learning objectives. This has turned out to be an advantage since it forces faculty to develop clear, measurable learning objectives for their courses. The instructor must also structure assignments so as to provide students with the opportunity to demonstrate mastery of the objectives. It has been found that when this is not the case, the students will request opportunities to demonstrate accomplishment of the missing objectives even if this means extra work for them.

Second, this technique reinforces the assessment philosophy promoted by ABET. By building assessment of the course into the grading system already required we are able to tie our measures of course effectiveness directly to the students' documented accomplishment of course objectives. Furthermore, the technique simplifies the preparation of documentation for periodic ABET program reviews. In addition, it makes the student an active participant in the review process. We have found that student interest in accreditation issues has risen and students are making more frequent suggestions on possible ways of improving courses. It has also helped instill ABET's closed loop correction philosophy into an operational level and to help institutionalize it. This approach makes the connections between class objectives and class work much clearer for all involved.

Third, we have not seen that this technique has had a great effect on the students' focus on grades. Most students think of the preparation of their assessment and portfolio as just another class assignment rather than an opportunity to reflect on what they've learned. The authors plan to examine modifications of the technique that encourage more reflection. Finally, our hopes that the technique would permit the measurement of attitudinal objectives have not been realized. Students seem to have as much difficulty observing and reflecting on their attitudes as instructors have trying to estimate them.

\section{$\underline{\text { Conclusions }}$}

In fourteen classes over 3 years, the authors have found this self-assessment approach to be useful to get students to think about their overall performance vis-à-vis the class objectives. Although useful, it is not a panacea for all the problems of grading and assessment. Specific conclusions are:

1) The described method adds discipline to the class objective setting process. It forces the instructor to have good objectives that are well thought out. It also forces the instructor to consider assignments and tests in the context of students' use of them for selfassessment against the objectives.

2) It encourages students to consider their performance vis-à-vis the objectives. Although the statistical evidence is slight currently, there appears to be good correlation between the instructor's view of performance and the students' self-assessment.

3) This method provides a ready scheme for closed-loop evaluation of a class and in particular the class objectives. This simplifies preparation of documentation files for ABET review.

Proceedings of the 2004 American Society for Engineering Education Annual Conference and Exposition Copyright (C) 2004, American Society for Engineering Education 
4) There is still no good approach within this context to evaluate the attitudinal objectives of a class.

\section{$\underline{\text { References }}$}

${ }^{1}$ Jalkio, J., "Using Self-Assessment and Student Generated Portfolios for Assessment of Student Learning and Course Effectiveness, Proceedings of the 2002 American Society of Engineering Education Annual Conference, June 2002

${ }^{2}$ Wankat, P. and Oreovicz, F., "Teaching-hit your mark", ASEE Prism, Nov 2001.

${ }^{3}$ Guskey, T. R., "Helping standards make the grade", Educational Leadership, vol 59, No. 1, Sept 2001, pp20-27.

${ }^{4}$ Hochstein, J.I. and Perry, E. H., “Direct Competency Testing - Is It For You?", Proceedings of the 1999 ASEE Annual Conference

${ }^{5}$ Angelo, T.A. and Cross, K. P., Classroom Assessment Techniques - A Handbook for College Teachers, $2^{\text {nd }}$ ed., Jossey-Bass, San Francisco, 1993.

${ }^{6}$ Handley, M. K., "Portfolio Assessment as a Measure of Student and Program Success", Proceedings of the 1999 ASEE Annual Conference.

${ }^{7}$ Falchikov, N. and Boud, D. "Student Self-Assessment in Higher Education: A Meta-Analysis", Review of Educational Research, vol. 59, pp.395-430.

${ }^{8}$ Gopinath, C., “Alternatives to Instructor Assessment of Class Participation”, Journal of Education for Business, vol. 75, no 1, Sept 1999, pp 10-14.

${ }^{9}$ International Organization for Standardization, International Vocabulary of Basic and General Terms, $2^{\text {nd }}$ edition, ISO Switzerland, 1993

\section{CHRISTOPHER S. GREENE}

Chris Greene received his Ph.D. in Electrical Engineering from the Massachusetts Institute of Technology (MIT) and proceeded to a 25 year career in industry. At Honeywell, he did research on adaptive control and navigation systems before becoming Program Manager for several large aerospace programs. At Horton and Nexen, he. was responsible for the development of industrial control products. In 2002, Dr. Greene joined the engineering department at the University of St. Thomas where he currently teaches classes in signals and systems, controls and digital design.

\section{JEFFREY A. JALKIO}

Jeff Jalkio received his $\mathrm{PhD}$ in Electrical Engineering from the University of Minnesota and worked for several years in industry in the fields of optical sensor design and process control. In 1984, he co-founded CyberOptics Corporation with Dr. Steve Case, where he headed research and development. In 1997 he returned to academia, joining the engineering faculty of the University of St. Thomas where he teaches courses in electronics, mechatronics, controls, and design. 